\title{
ON A CLASS OF NONLOCAL ELLIPTIC PROBLEMS WITH CRITICAL GROWTH
}

\section{O. Alves, F. J. S. A. CorrêA And G. M. Figueiredo}

Abstract. This paper is concerned with the existence of positive solutions to the class of nonlocal boundary value problems of the Kirchhoff type

$$
-\left[M\left(\int_{\Omega}|\nabla u|^{2} d x\right)\right] \Delta u=\lambda f(x, u)+u^{5} \text { in } \Omega, u(x)>0 \text { in } \Omega \text { and } u=0 \text { on } \partial \Omega,
$$

where $\Omega \subset \mathbb{R}^{N}$, for N=1,2 and 3, is a bounded smooth domain, $M$ and $f$ are continuous functions and $\lambda$ is a positive parameter. Our approach is based on the variational method.

Mathematics subject classification (2010): 34B18, 34C11, 34K12, 35J25, 45M20.

Keywords and phrases: variational methods, nonlocal problems, Kirchhoff equation, critical growth.

\section{REFERENCES}

[1] C. O. Alves, Existence of radial solutions for a class of $p(x)$-Laplacian equations with critical growth, to appear in Diff. Int. Eq., (2009).

[2] C. O. Alves, F. J. S. A. CORRÊA, On existence of solutions for a class of problem involving a nonlinear operator, Comm. Appl. Nonlinear Anal., 8 (2001), 43-56.

[3] C. O. Alves, F. J. S. A. CorrêA, T. F MA, Positive solutions for a quasilinear elliptic equation of Kirchhoff type, Comput. Math. Appl., 49 (2005), 85-93.

[4] A. Ambrosetti, P. H. Rabinowitz, Dual variational methods in critical point theory and apllications, J. Functional Analysis, 14 (1973), 349-381.

[5] J. G. Azorero, I. P. Alonso, Multiplicity of solutions for elliptic problems with critical exponent or with a nonsymmetric term, Trans. Amer. Math. Soc. , 323, 2 (1991), 877-895.

[6] H. Brezis, L. Nirenberg, Positive solutions of nonlinear elliptic equations involving critical Sobolev exponents, Comm. Pure Appl. Math., 36 (1983), 437-477.

[7] F. J. S. A. CorrêA, G. Figueiredo, On an elliptic equation of $p$-Kirchhof type via variational methods, Bull. Aust. Math. Soc., 74, 2 (2006), 263-277.

[8] F. J. S. A. CorrêA, S. D. B. Menezes, Existence of solutions to nonlocal and singular elliptic problems via Galerkin method, Electron. J. Differential Equations, (2004), 1-10.

[9] G. KirchHoff, Mechanik, Teubner, Leipzig, 1883.

[10] J. L. Lions, On some questions in boundary value problems of mathematical physics, International Symposium on Continuum, Mechanics and Partial Differential Equations, Rio de Janeiro (1977), Mathematics Studies, Vol. 30, North-Holland, Amsterdam, (1978), 284-346.

[11] T. F. MA, Remarks on an elliptic equation of Kirchhoff type, Nonlinear Anal., 63, 5-7 (2005), 19671977.

[12] P. L. LiOns, The concentration-compactness principle in the calculus of variations. The limit case, Rev. Mat. Iberoamericana, 1 (1985), 145-201.

[13] K. Perera, Z. Zhang, Nontrivial solutions of Kirchhoff-type problems via the Yang index, J. Differential Equations, 221 (2006), 246-255.

[14] M. WilLeM, Minimax Theorems, Birkhäuser, 1996. 